\title{
Cooperação territorial: análise do capital social e da governança local do Arranjo Produtivo Local de Móveis do Sudoeste do Paraná
}

\author{
Marcos Junior Marini \\ Universidade Tecnológica Federal do Paraná \\ Gilcindo de Castro Corrêa Neto \\ Universidade Tecnológica Federal do Paraná \\ Sebrae Paraná - Escritório Pato Branco (Paraná)
}

\begin{abstract}
Resumo
Uma das estratégias indicada em pesquisas acadêmicas sobre desenvolvimento regional corresponde às aglomerações produtivas concentradas geograficamente, a partir da organização dos agentes em rede para a obtenção de vantagens competitivas pelas práticas de cooperação territorial. Nesse sentido, o artigo objetivou analisar o capital social e a condução da governança local no contexto do APL de Móveis do Sudoeste do Paraná. A presente pesquisa classifica-se como descritiva de caráter exploratório, com uma abordagem quanti-qualitativa, a partir do método de análise documental e entrevistas estruturadas. O questionário foi o principal instrumento de coleta de dados em uma pesquisa de campo com o conjunto de agentes do arranjo produtivo, incluindo dezenove empresários do APL, cinco agentes de apoio e a governança local. Os resultados da pesquisa apontaram para bons níveis de capital social no APL, com indicadores positivos quanto ao grau de contribuição no relacionamento, na confiança e cooperação entre os agentes, na qualidade e utilidade das informações trocadas. As métricas da rede social (densidade e reciprocidade) resultaram em valores medianos, enquanto o quesito referente à participação em reuniões obteve os piores resultados. Em relação à avaliação da governança local, todos os elementos analisados resultaram em valores considerados fracos. Em síntese, a avaliação do binômio capital social e governança local demonstrou que para a efetiva execução de ações conjuntas em consonância com as práticas de cooperação territorial, torna-se fundamental a existência de uma governança local mais atuante na gestão do APL.
\end{abstract}

Palavras-chave: Cooperação territorial. Arranjo Produtivo Local. Capital Social. Governança Local. Sudoeste do Paraná. 


\title{
Territorial cooperation: analysis of the social capital and local governance of the Furniture Cluster of the Southwest of Paraná
}

\begin{abstract}
One of the strategies indicated in academic research on regional development corresponds to geographically concentrated productive agglomerations, based on the organization of network agents to obtain competitive advantages through territorial cooperation practices. In this sense, the article aimed to analyze the social capital and the conduction of local governance in the context of the Cluster of Furniture of the Southwest of Paraná. The present research is classified as exploratory descriptive, with a quanti-qualitative approach, based on the method of documental analysis and structured interviews. The questionnaire was the main instrument of data collection in a research with the set of agents of the productive arrangement, including nineteen cluster business owners, five support agents and local governance. The results of the research pointed to good levels of social capital in the analyzed cluster, with positive indicators regarding the degree of contribution in the relationship, trust and cooperation between the agents, in the quality and usefulness of the information exchanged. The metrics of the social network (density and reciprocity) resulted in median values, while the question of participation in meetings obtained the worst results. Regarding the evaluation of local governance, all elements analyzed resulted in values considered to be weak. In summary, the evaluation of the binomial social capital and local governance has shown that for the effective execution of joint actions in line with territorial cooperation practices, it is fundamental to have a more active local governance in the management of cluster.
\end{abstract}

Keywords: Territorial cooperation. Cluster. Social Capital. Local Governance. Southwest of Paraná.

\section{Cooperación territorial: análisis del capital social y de la gobernanza local del Cluster de Muebles del Sudoeste de Paraná}

\section{Resumen}

Una de las estrategias indicadas en investigaciones académicas sobre desarrollo regional corresponde a las aglomeraciones productivas concentradas geográficamente, a partir de la organización de los agentes en red para la obtención de ventajas competitivas por las prácticas de cooperación territorial. En este sentido, el artículo objetivó analizar el capital social y la conducción de la gobernanza local en el contexto del Cluster de Muebles del Sudoeste de Paraná. La presente investigación se clasifica como descriptiva de carácter exploratorio, con un abordaje cuantitativo, a partir del método de análisis documental y entrevistas estructuradas. El cuestionario fue el principal instrumento de recolección de datos en una investigación de campo con el conjunto de agentes del arreglo productivo, incluyendo diecinueve empresarios del cluster, cinco agentes de apoyo y la gobernanza local. Los resultados de la investigación apuntaron a buenos niveles de capital social en el cluster, con indicadores positivos en cuanto al grado de contribución en la relación, en la confianza y cooperación entre los agentes, en la calidad y utilidad de las informaciones intercambiadas. Las métricas de la red social (densidad y reciprocidad) resultaron en valores medianos, mientras que el tema referente a la participación en reuniones obtuvo los peores resultados. En relación a la evaluación de la gobernanza local, todos los elementos analizados resultaron en valores considerados débiles. En síntesis, la evaluación del binomio capital social y gobernanza local demostró que para la efectiva ejecución de acciones conjuntas en consonancia con las prácticas de cooperación territorial, se torna fundamental la existencia de una gobernanza local más actuante en la gestión del cluster. 
Palabras clave: Cooperación territorial. Cluster. Capital social. Gobernanza local. Sudoeste de Paraná.

\section{Introdução}

As mudanças dos sistemas de produção industrial e os avanços tecnológicos observados a partir da segunda metade do século XX despertaram o interesse pelo desenvolvimento territorial, como alternativa para as economias periféricas, frente às imposições do modelo hegemônico vigente.

Nesse sentido, uma das estratégias indicada em pesquisas acadêmicas sobre desenvolvimento regional corresponde às aglomerações produtivas concentradas geograficamente. No Brasil, os Arranjos Produtivos Locais - APLs estão sendo cada vez mais objeto de políticas públicas, visando potencializar as externalidades positivas geradas, além de alavancar a competitividade de pequenas e médias empresas e melhorar o ambiente de negócios da região como um todo (CASSIOLATO; LASTRES, 2003; CAMPOS, 2004; SUZIGAN, 2006; COSTA, 2010).

Em síntese, os APLs se constituem em uma rede territorial constituída para a busca da eficiência coletiva e do desenvolvimento local/regional, cujos princípios se baseiam na confiança e na capacidade de cooperação entre os seus agentes, bem como nos mecanismos de condução desta rede territorial pela sua governança local. Ademais, ressalta-se que, neste cenário de investigação, optou-se por um recorte a partir de duas características básicas de um APL: o capital social e a governança local.

Como encaminhamento, o objeto selecionado para o presente estudo foi o APL de Móveis do Sudoeste do Paraná, devido à relevância do setor de móveis e madeira para a economia da região (IPARDES, 2006; IPARDES, 2009; AGÊNCIA, 2016). Logo, o artigo objetiva analisar o capital social dos agentes participantes e a condução da governança local, no caso específico, do APL de Móveis da região Sudoeste do Paraná.

O artigo está organizado em cinco seções, incluindo esta introdução, uma breve fundamentação teórica envolvendo a temática dos APLs e o binômio capital social e governança local, aspectos da abordagem metodológica, a análise e a interpretação dos resultados da pesquisa, bem como as considerações finais.

\section{Arranjos Produtivos Locais como uma estratégia de cooperação territorial}

No Brasil, as aglomerações produtivas concentradas geograficamente são denominadas de APLs, com a nomenclatura sendo difundida por meio do Ministério de Ciência e Tecnologia - MCT, no final da década de 1990 (COSTA, 2010). Nesse sentido, um dos conceitos apresentados na literatura aponta que um APL corresponde a:

um sistema localizado de agentes econômicos, políticos e sociais ligados a um mesmo setor ou atividade econômica, que possuem vínculos produtivos e institucionais entre si, de modo a proporcionar aos produtores um conjunto de benefícios relacionados com a aglomeração das empresas. (SUZIGAN, 2006, p. 3). 
A partir do início dos anos 2000, o governo federal instituiu a Política Nacional de Apoio aos APLs, por meio da incorporação do tema no âmbito do Plano Plurianual - PPA (2004-2007), e subsequentes, além da criação do Grupo de Trabalho Permanente para Arranjos Produtivos Locais - GTP/APL, entidade composta por 33 instituições governamentais e não governamentais, cuja secretaria técnica está diretamente ligada ao Ministério do Desenvolvimento, Indústria e Comércio Exterior - MDIC (COSTA, 2010; MARINI; SILVA, 2013).

Nesse sentido, muitas políticas públicas voltadas para o desenvolvimento regional passaram a ser formuladas buscando a articulação governamental para o apoio, fomento e estruturação de APLs, os quais sejam formados, principalmente, por micro e pequenas empresas - MPEs presentes em um território.

Corroborando esse debate, Meirelles Júnior (2013) afirma que os APLs podem se tornar importante fonte de desenvolvimento por meio da geração de vantagens competitivas, principalmente quando estas são construídas pelo enraizamento de capacidades produtivas e inovativas e pelo incremento do capital social oriundo da integração dos atores locais, refletindo na promoção da competitividade e da sustentabilidade dos empreendimentos presentes no território onde o arranjo produtivo está localizado.

Segundo Marini et al. (2012), a consolidação de APLs que visam alcançar vantagens competitivas e eficiência coletiva necessita, sobretudo, de articulação e sinergia entre os mais diversos atores locais, que compartilham dos mesmos valores regionais. Esses autores ressaltam que a simples ocorrência de aglomerações industriais localizada em uma mesma região ou localidade, não determina, por si só, a existência de um APL, sendo necessário também considerar os aspectos territoriais.

Em continuidade, Marini et al. (2012) propõem uma matriz de interdependência (Figura 1) para APLs, visando representar o cenário de interação entre os componentes de um APL e o respectivo território, representado pela interação multidimensional. 
Figura 1. Matriz de Interdependência para Arranjo Produtivo Local

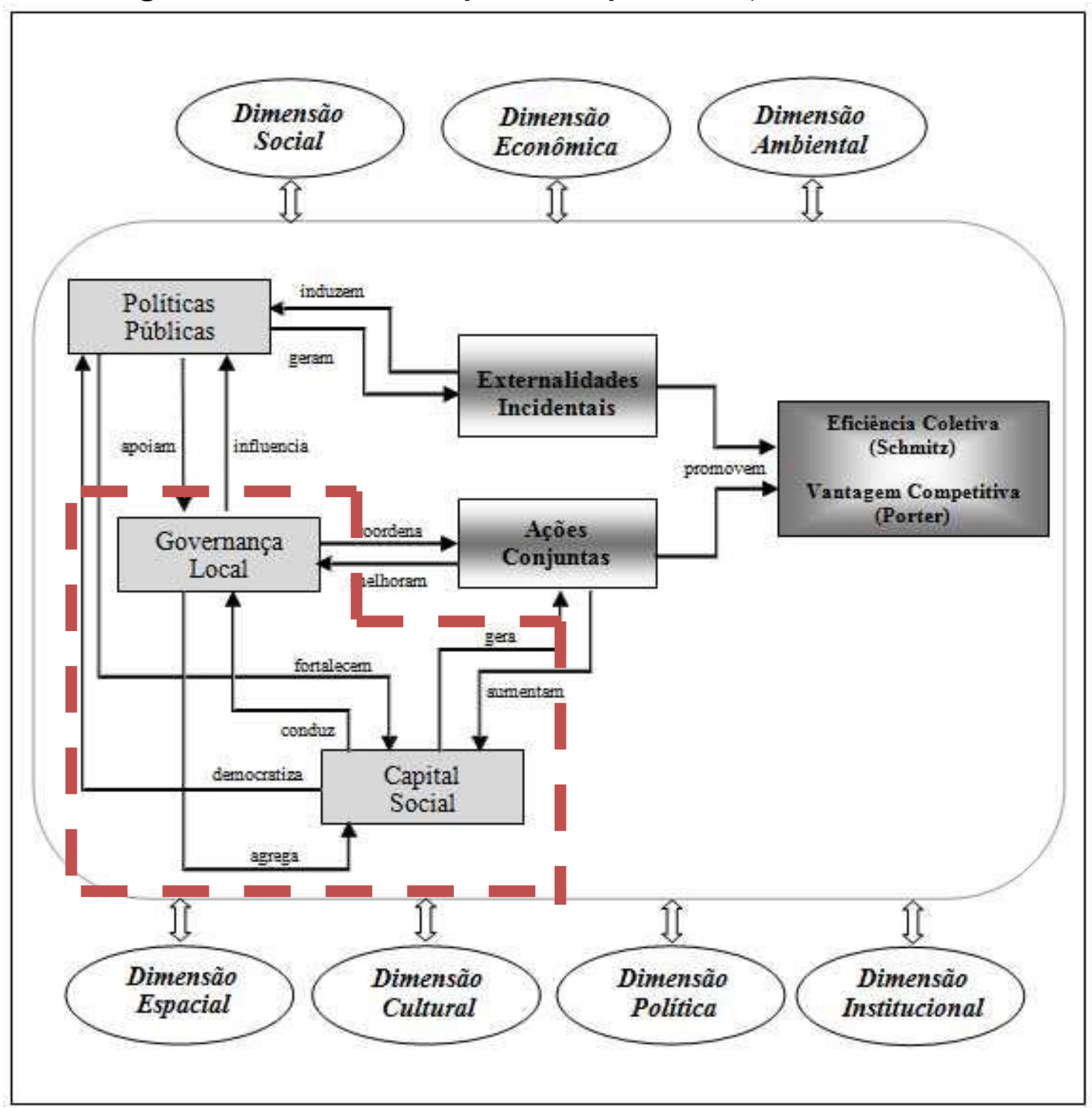

Fonte: Marini et al. (2012).

Diante do exposto, a proposta matricial aponta para a existência de uma interdependência entre os componentes internos, incluindo capital social, governança local, ações conjuntas, políticas públicas, externalidades incidentais, os quais interagem na geração da eficiência coletiva e vantagem competitiva para o APL (MARINI et al., 2012).

Ainda nessa questão, para o presente artigo, optou-se em utilizar os dois componentes da matriz que foram destacados na área interna da região pontilhada, correspondendo ao capital social e à governança local, por se tratarem de elementos fundamentais durante o processo de coordenação das ações conjuntas (cooperação) para a geração da eficiência coletiva e das vantagens competitivas no cenário de cooperação territorial. 


\subsection{Capital social}

As discussões teóricas revelaram a importância das relações econômicas, sociais e institucionais do ambiente onde a atividade produtiva está inserida. Assim, desde a década de 1990, observa-se uma maior valorização das estruturas e redes sociais que formam o território, vinculando o componente sócio-cultural às questões territoriais (PUTNAM, 1996; ALBAGLI; MACIEL, 2003; WOOLCOCK et al., 2003).

Nessa abordagem, Putnam (1996) elaborou seus estudos sobre a temática do capital social, pesquisando o desempenho das instituições, governos e empresas de diferentes regiões da chamada Terceira Itália, identificando diferenciadas relações de sinergia entre os atores mencionados. Para esse autor, capital social pode ser conceituado como segue:

\footnotetext{
capital social refere-se a aspectos da organização social, tais como redes, normas e confiança que facilita coordenação e cooperação para benefícios mútuos. Capital social aumenta os benefícios de investimento em capital físico e capital humano. (PUTNAM, 1996, p.67).
}

Nesse debate, é importante destacar que North (1990) e Putnam (1996) consideram que as instituições são as "regras do jogo", ou seja, as regulamentações utilizadas pelas arenas coletivas para a tomada de decisões sobre possíveis resoluções de problemas e conflitos. As instituições se constituem em instrumentos para se atingir objetivos concretos da coletividade e não apenas meros protocolos para oficialização de acordos. Logo, o êxito institucional significa capacitar os atores para resolverem suas próprias divergências, considerando suas diferentes posições e necessidades.

Coleman (1988) afirma que a formação do capital social está vinculada com as relações de confiança entre os indivíduos e não com as relações econômicas. Portanto, essa relação de confiabilidade gera expectativas de comprometimento de retribuição entre os membros envolvidos, o que estaria diretamente relacionado com a capacidade de articulação de forças endógenas, expressa por um novo sujeito coletivo que busca o desenvolvimento regional (ABRAMOVAY, 2000).

Segundo Casarotto Filho e Pires (2001), o capital social pode ser fortalecido pela construção de práticas cooperativas, que podem ser estabelecidas pelo intercâmbio entre as empresas envolvidas, objetivando a definição da área de atuação, da visão estratégica, do levantamento de problemas comuns e suas soluções, bem como, no direcionamento e nas relações com os parceiros.

Em continuidade, ressalta-se que a eficiência coletiva derivada das ações conjuntas de um APL é resultado do capital social que é construído coletivamente pelos próprios agentes, a partir do estabelecimento de normas, relações de confiança, práticas de cooperação, sistemas de governança e reciprocidade, entre outros (COLEMAN, 1988; PUTNAM, 1996; ABRAMOVAY, 2000; CASAROTTO FILHO; PIRES, 2001; ALBAGLI; MACIEL, 2003). 


\title{
2.2 Governança Local
}

Conforme Dallabrida e Becker (2003), o conceito de governança local diz respeito à capacidade que a sociedade de um determinado território possui para coordenar as ações relacionadas aos assuntos públicos, por meio do envolvimento e cooperação de diversos atores regionais, implicando diretamente na capacidade cooperativa territorial. Desse modo, a estrutura do sistema de governança é um elemento básico que propicia a ligação entre os outros elementos, ou seja, efetua a ligação entre os atores/agentes locais/regionais, instrumentos e o ambiente.

Os fundamentos para as atividades cooperativas representam a estrutura da governança da rede, demonstrando como esta é gerenciada, regulamentada e organizada. Essa estrutura no âmbito da produção industrial está baseada na força das instituições regionais, que norteiam o comportamento dos atores envolvidos na cadeia produtiva local (CAMPOS, 2004).

Para que os objetivos coletivos de uma rede sejam atingidos com êxito, a coordenação das atividades conjuntas atribuídas aos agentes é "uma das funções básicas do sistema de governança" (CASTRO, 2013, p.82).

A conceituação de governança, especificamente para APLs está diretamente relacionada com a capacidade que os atores participantes da coordenação possuem para gerir e conduzir "as inter-relações produtivas, comerciais, tecnológicas e outras, influenciando decisivamente o desenvolvimento do sistema ou arranjo local" (SUZIGAN; GARCIA; FURTADO, 2007, p.425). Ainda sobre esse aspecto, os autores enfatizam o seguinte:

\begin{abstract}
assim entendida, a governança é um dos aspectos mais complexos dentre os que caracterizam a dimensão espacial das atividades produtivas e inovativas. A complexidade decorre, por um lado, do difícil equilíbrio que a forma de governança deve manter entre cooperação e competição no âmbito do APL e, por outro lado, da miríade de fatores que condicionam a governança. (SUZIGAN; GARCIA; FURTADO, 2007, p.425).
\end{abstract}

Diante do exposto, ressalta-se que o desenvolvimento de arranjos produtivos está condicionado à capacidade dos agentes envolvidos em se articular e conduzir uma governança local, capaz de incentivar os benefícios coletivos para a rede, sendo que as formas de coordenação podem variar conforme as características específicas de cada tipo de sistema produtivo (SUZIGAN; GARCIA; FURTADO, 2007; MARINI; SILVA, 2012).

Nesse horizonte, a governança local de APLs envolve as várias formas de articulação, coordenação e intervenção no processo decisório, que conta com a participação de diversos atores locais, como os empresários de toda a cadeia produtiva, entidades de apoio, trabalhadores, entidades de ensino, órgãos públicos, entre outras instituições locais e regionais (CASSIOLATO; SZAPIRO, 2003).

Conforme Farah Jr. et al. (2006), a criação de uma rede de cooperação para aglomerações produtivas é fundamental para o fortalecimento do capital social e das práticas cooperativas entre os atores que buscam vantagens competitivas. Sendo assim, "na medida em que as ações deixam de ser individualizadas e tornamse mais coletivas, torna-se necessária a constituição de um processo de coordenação das diversas ações de modo a garantir a formação de sinergias". 
(FARAH JR. et al., 2006, p. 3). Contudo, esse autor argumenta que, no caso de governança específica para APLs, não existe uma receita única.

Portanto, a governança local pode assumir várias formas para estimular a competitividade e a relação de cooperação entre os agentes do APL, o que propicia a geração de ações conjuntas e favorece as condições para o desenvolvimento regional. Logo, uma estrutura de governança local define-se pela coordenação das ações coletivas e coloca-se entre as instituições e os agentes locais (ORTEGA; SILVA, 2011).

Diante do exposto, o conceito de governança em APLs está relacionado com as diferentes formas de coordenação, intervenção e participação nos processos de tomada decisão dos diferentes atores/agentes que participam desta organização territorial, visando propiciar um ambiente que seja construtivo para a execução das diversas atividades que envolvem a organização dos fluxos de produção e comercialização, assim como o processo de geração, disseminação e uso de conhecimentos nesta rede local/regional (CASSIOLATO; LASTRES, 2003).

A partir desses conceitos, é possível afirmar que, para o sucesso e a sustentabilidade econômica de um APL, o qual está baseado nas práticas de cooperação territorial, a governança passa a ser um fator fundamental, em que as vantagens competitivas locais são maximizadas, através de um planejamento de ações, as quais são promovidas pela cooperação de um conjunto de agentes e instituições regionais (FUINI, 2014).

\section{Materiais e métodos}

Esta seção apresentará os procedimentos metodológicos que foram utilizados para atender ao propósito estabelecido para esta pesquisa, incluindo a classificação metodológica, as técnicas e instrumentos para a coleta de dados, bem como as ferramentas utilizadas para a compilação dos dados coletados e a interpretação dos resultados.

A abordagem metodológica adotada possibilita classificar esta pesquisa como descritiva exploratória, com a aplicação do método de estudo de caso, especificamente no contexto do APL de Móveis do Sudoeste do Paraná.

Quanto aos procedimentos para a coleta e interpretação dos dados, o presente trabalho utilizou uma abordagem de análise quantiqualitativa, baseada em fontes primárias e secundárias. Para os dados secundários, foi elaborada uma pesquisa documental, com base em relatórios obtidos junto às principais instituições relacionadas com o setor moveleiro do Sudoeste do Paraná, bem como repositórios governamentais, incluindo Instituto Brasileiro de Geografia e Estatística - IBGE, Relação Anual de Informações Sociais/Ministério do Trabalho e Emprego RAIS/MTE, Instituto Paranaense de Desenvolvimento Econômico e Social - IPARDES, entre outros.

Em relação às fontes primárias, foi utilizada a técnica de pesquisa de campo, por meio de entrevistas, com a aplicação de um questionário estruturado visando à avaliação do capital social e da governança local, utilizando-se de uma escala de 1 a 10. Nessa direção, inicialmente foram identificados os agentes participantes do APL selecionado, incluindo a relação de empresários e agentes de apoio, que foi obtida por meio de documentos coletados junto à governança local 
do APL e do Sindicato das Indústrias Madeireiras e Moveleiras do Sudoeste do Paraná - SINDIMADMOV.

Com esse encaminhamento, a pesquisa de campo foi realizada com a aplicação dos questionários envolvendo um conjunto de 25 entrevistados, incluindo 19 empresários (do total de vinte e um que participam do APL), cinco agentes de apoio (SINDIMADMOV, Federação das Indústrias do Estado do Paraná - FIEP, Serviço Social da Indústria/Serviço Nacional de Aprendizagem Industrial Paraná SESI-SENAI PR, Serviço de Apoio às Micro e Pequenas Empresas do Paraná - SEBRAE PR, Associação Comercial e Empresarial de Francisco Beltrão), além de um representante da governança local.

Nesse sentido, Gil (2008) afirma que a entrevista é uma das técnicas mais utilizadas para pesquisas de cunho social, onde, normalmente, gera-se um diálogo assimétrico entre a pessoa que busca informações (pesquisador) e outra, que atua como fonte de informações (entrevistado).

Ainda em relação às entrevistas, é importante destacar que foi solicitado aos respondentes que fosse considerado um recorte temporal incluindo os últimos cinco anos, ou seja, o período entre 2013 e 2017. Logo, para a governança local, foi realizada uma entrevista com a empresária que atuou na coordenação deste APL no período entre 2012 e 2015, pois, como pode ser visto no quadro 1, no último biênio ocorreu vacância na função de presidente deste arranjo produtivo.

\section{Quadro 1. Situação da Governança Local do Arranjo Produtivo Local em discussão}

\begin{tabular}{|c|c|c|c|c|c|}
\hline \multicolumn{6}{|c|}{ Governança APL Móveis do Sudoeste do PR - 2006 - 2017} \\
\hline $2006-2007$ & 2008-2009 & $2010-2011$ & $2012-2013$ & $2014-2015$ & $2016-2017$ \\
\hline $\begin{array}{c}\text { Empresário } \\
\text { C16 }^{1}\end{array}$ & $\begin{array}{c}\text { Empresário } \\
\text { C16 }\end{array}$ & $\begin{array}{c}\text { Empresária } \\
C_{1} 8^{2}\end{array}$ & $\begin{array}{c}\text { Empresária } \\
\text { C18 }\end{array}$ & $\begin{array}{c}\text { Empresária } \\
\text { C18 }\end{array}$ & $\begin{array}{c}\text { Sem } \\
\text { Governança }\end{array}$ \\
\hline
\end{tabular}

Fonte: elaborado pelos autores.

Ademais, o instrumento de coleta de dados utilizado nas entrevistas foi baseado nos principais apontamentos da literatura, os quais podem ser vistos neste artigo nas subseções 2.1 (capital social) e 2.2 (governança local). Assim, a avaliação do capital social considerou os seguintes elementos: confiança; nível de cooperação; participação no APL; nível de relacionamento; troca de informações; engajamento e comprometimento; densidade da rede; reciprocidade entre os participantes. Para a governança local, foram considerados: capacidade de coordenação (gestão); capacidade de articulação (concertação social); poder ou influência na resolução de conflitos; transparência na gestão; práticas democráticas na tomada de decisão; dificuldades da governança local.

Em continuidade, a tabulação dos dados da pesquisa de campo foi realizada a partir de quatro ferramentas, incluindo: Software Microsoft Excel (sistematização dos resultados e respectivos cálculos); Software Microsoft Word (transcrição de tabelas e diagramação textual); Software Ucinet for Windows (cálculo de

\footnotetext{
${ }^{1}$ Empresário C16 é proprietário da empresa Laris Indústria e Comércio de Móveis Ltda, de Realeza (PR).

${ }^{2}$ Empresária C18 é proprietária da empresa Francisco Smaniotto ME, de Salgado Filho (PR).
} 
indicadores de análise de redes sociais); Software NetDraw (criação da representação gráfica dos sociogramas).

\section{Análise dos resultados e discussões}

Esta seção visa apresentar os principais resultados desta pesquisa, a partir da discussão dos dados obtidos na coleta de dados. Inicialmente, será apresentada uma breve caracterização do cenário de investigação, seguindo com a análise dos elementos do capital social e da governança local no contexto do APL de Móveis da região sudoeste do Paraná.

\subsection{Caracterização do cenário de investigação}

Uma importante característica do segmento industrial moveleiro no país é a sua organização em polos produtivos, sendo que alguns são reconhecidos como APLs formalizados (GAZIRI, 2010). Segundo o estudo realizado em 2008 para a identificação e mapeamento das aglomerações produtivas no Paraná, o Estado possui cinco arranjos produtivos do setor moveleiro: APL de Móveis de Arapongas; APL de Móveis de Metal de Ponta Grossa; APL de Móveis de Madeira de Rio Negro; APL de Madeiras e Esquadrias de União da Vitória; e o objeto deste trabalho - o APL de Móveis do Sudoeste (IPARDES, 2009).

Em relação ao lócus de pesquisa, ressalta-se que a ocupação e o desenvolvimento do Sudoeste do Paraná, no período que compreende os anos 1930 até o final dos anos 1960, apresentou destaque na atividade madeireira, principalmente pela exploração da madeira do nativo pinheiro araucária (FLORES, 2009). A partir dos anos 1970, a indústria moveleira desta região foi gradativamente ganhando força com as serrarias, até tornar-se um importante polo setorial, com, atualmente, em torno de 250 empresas distribuídas pela região, com destaque para os municípios de Francisco Beltrão, Pato Branco, Chopinzinho, Ampére e Realeza (SINDIMADMOV, 2016).

O APL surgiu no ano de 2006, a partir de uma iniciativa de empresários locais com alguns agentes de apoio e o Sindicato das Indústrias Madeireiras e Moveleiras do Sudoeste do Paraná (SINDIMADMOV), cuja base territorial é formada por 21 municípios, como pode ser visto na figura 2, os quais estão identificados com estrelas. 
Figura 2. Localização do APL de Móveis do Sudoeste do Paraná

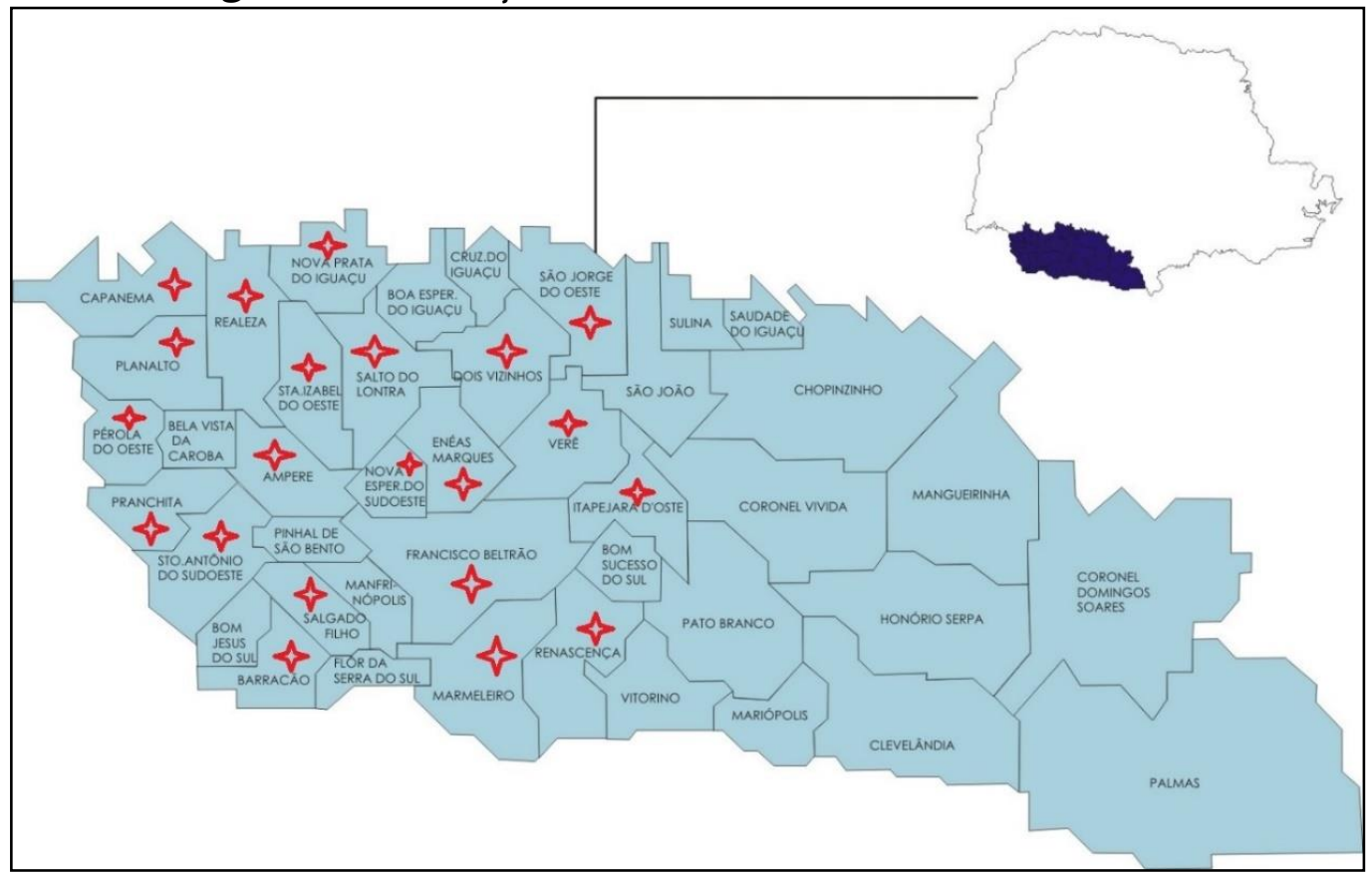

Fonte: adaptado de IPARDES (2016).

Segundo os dados do SINDIMADMOV (2016), esse arranjo produtivo é formado por 22 empresas produtoras de móveis, representando $57 \%$ das associadas ao sindicato regional, as quais produzem móveis em série e sob medida para o mercado interno, e geram em torno de 1.300 empregos diretos na região.

Como encaminhamento, a próxima subseção apresentará a compilação dos resultados obtidos na pesquisa de campo, a partir da análise dos elementos presentes no capital social dos participantes e a condução da governança local do APL em discussão.

\subsection{Análise do binômio capital social e governança local}

Com a intenção de alcançar o principal objetivo proposto para esta pesquisa, que preconiza analisar os elementos do capital social e a condução da governança local do APL de Móveis do Sudoeste do Paraná, serão apresentados e discutidos os principais resultados. Inicialmente, cabe destacar que, para um melhor entendimento e tabulação dos resultados encontrados, optou-se em utilizar uma escala numérica composta por quatro níveis, a saber: BAIXO (o a 2,50), FRACO $(2,51$ a 5,00), BOM (5,01 a 7,50) e ÓTIMO (7,51 a 10,0).

$\mathrm{Na}$ análise dos elementos do capital social do APL em discussão, destacou-se a contribuição do relacionamento por parte dos empresários, resultando em uma média de 8,2, que pode ser considerada ótima. No entanto, é fraco o nível de participação dos empresários em reuniões do APL, pois resultou em uma média de 4,1 (fraca). Os próprios empresários respondentes reconheceram a existência de um forte relacionamento informal, que pode justificar essa desproporção entre esses indicadores. Em relação aos agentes de apoio, o grau médio de contribuição no relacionamento foi de 6,2 , podendo ser considerado bom, mas a média na participação em reuniões também não foi significativa, resultando em uma média 
5,0 (fraca participação). Esses indicadores que demonstraram uma baixa participação no APL são justificáveis pela própria ausência formal de uma governança local no arranjo produtivo, como foi apresentado anteriormente no quadro 1.

Ainda nesta questão, é possível perceber que a fraca participação em reuniões também contribuiu negativamente com outros indicadores levantados na pesquisa, como ocorreu com o nível de engajamento e comprometimento dos participantes do APL, pois a média geral dos 25 entrevistados foi de 4,8 (fraco). Nesse sentido, ressalta-se que as variáveis relacionadas ao engajamento e comprometimento, assim como a participação efetiva em atividades e reuniões no APL, são essenciais para o fortalecimento da rede e a construção do capital social (TEIXEIRA; SERRALVO, 2010).

Ainda na avaliação do capital social, a análise dos níveis de confiança é fundamental, pois é uma das variáveis básicas do capital social, e a existência de níveis elevados deste elemento indicam que os envolvidos possuem boas condições para o desenvolvimento de práticas conjuntas (PUTNAM, 2006; GRANOVETTER, 2007). Nesse quesito, o arranjo produtivo apresentou boas médias, sendo que resultou em 6,8 (bom) para os agentes de apoio, em 6,5 (bom) para o conjunto de empresários e, ainda, em uma média geral de todos os entrevistados de 6,4 (bom).

Nesta discussão, a literatura aponta que os princípios da confiança mútua podem contribuir diretamente com: a redução do comportamento vinculado ao oportunismo e à incerteza; diminuição da necessidade de incorporação de mecanismos de controle e monitoração de condutas e custos de contratos para a formação de APLs; melhoria na divisão do trabalho entre os participantes da rede, otimizando o processo produtivo, evitando retrabalhos; e, ainda, proporcionando a transferência de informações tácitas (SABOURIN; TEIXEIRA, 2002).

Em suma, no caso específico do APL de Móveis do Sudoeste do Paraná, o elemento confiança, de modo geral, apresentou indicadores favoráveis, o que evidencia a existência de uma base importante para o fortalecimento da rede de relacionamentos deste $\mathrm{APL}$, visando o desenvolvimento de cooperação territorial.

Essa questão também ficou evidenciada com a pesquisa de campo, pois a mesma revelou que os bons níveis de confiança entre os participantes deste arranjo produtivo está gerando bons resultados quanto ao nível de cooperação, como fica evidente nos resultados apresentados no gráfico 1, os quais demonstram uma média geral do grau de cooperação entre todos os agentes de 5,9 (bom). Porém, os agentes de apoio avaliaram esse elemento com uma média um pouco inferior $(5,6)$, mas ainda no nível bom dentro da escala.

A partir do compartilhamento de interesses, o capital social atua influenciando os agentes a agirem de forma cooperativa (UPHOFF, 2000). Por sua vez, o capital social de um APL depende do grau de cooperação e confiança existente entre os agentes e cria condições adequadas para sua a inserção em uma rede de relacionamentos promotora de inovações tecnológicas e processos de melhorias para o arranjo (GUSSONI, 2013). 


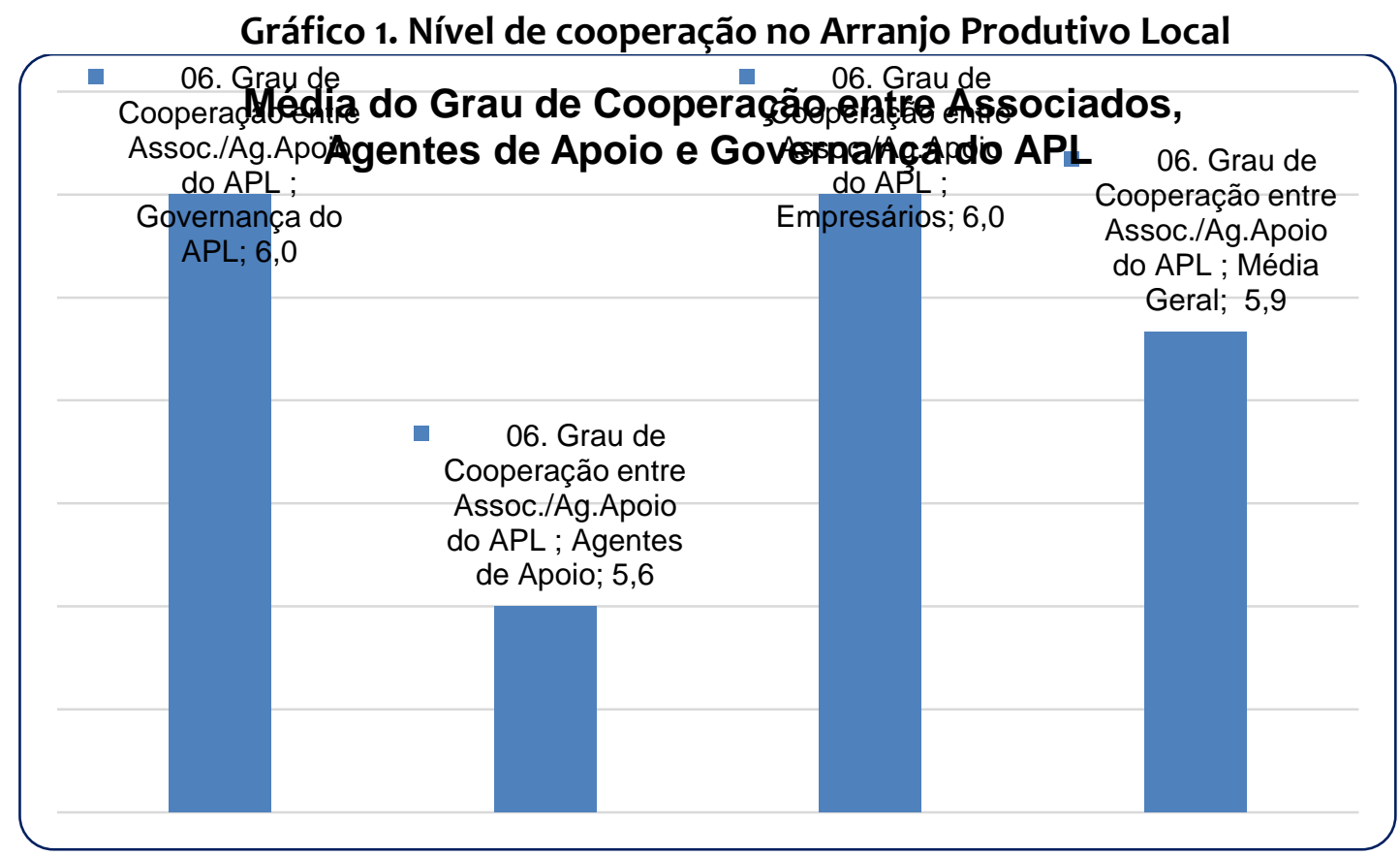

Fonte: elaborado pelos autores.

Outros elementos do capital social que foram avaliados com bons níveis foram a avaliação sobre a contribuição no conjunto do APL, com média geral de 7,0 (bom), bem como a qualidade e utilidade das informações trocadas entre os participantes, que apresentou um média geral de 7,3 (bom).

Em relação à periodicidade para a troca de informações entre os participantes, a indicação para uma ocorrência mensal foi a mais apontada pelos entrevistados, correspondendo a 32\%. Ademais, os extremos, ou seja, aqueles que apontaram que a periodicidade quanto à troca de informações ocorre semestralmente, correspondeu a $18 \%$ dos entrevistados, e aqueles que apontaram que a troca é mais intensiva, ocorrendo semanalmente (15\%) e a troca quinzenal, foi apontada por $9,7 \%$ do conjunto de entrevistados. Ainda, os resultados demonstram uma faixa preocupante de entrevistados que informaram que, mesmo participando do arranjo produtivo, não possuem a prática de troca de informações, pois esse indicador resultou em $21 \%$.

Ainda quanto à troca de informações, o estudo apontou que os meios mais utilizados pela rede de agentes do APL são: reuniões (18,42\%); email (18,42\%); aplicativos de mensagens online (16,68\%); eventos (14,91\%); visitas (14,91\%); conversas informais e contatos telefônicos $(8,77)$.

As discussões do capital social de um arranjo produtivo também passam pela necessidade de avaliar alguns indicadores relacionados à organização desta rede, a partir da utilização da metodologia de Análise de Redes Sociais - ARS. Neste sentido, uma rede social consiste de relações entre indivíduos ou organizações que são conectadas por meio de linhas criadas pela rede através das relações sociais mantidas por esses atores, incluindo relações de trabalho, amizade e troca de informações. Sendo assim, a dinâmica das redes só acontece a partir do estabelecimento de conexões entre seus atores (WASSERMAN; FAUST, 1994; SCOTT, 2000). 
Diante do exposto, uma das métricas utilizadas é o nível de densidade da rede, correspondendo ao indicador da conectividade no interior desta rede, ou seja, representa o número de ligações possíveis entre os atores. As redes densas possuem grande quantidade de conexões, e as redes chamadas esparsas são as portadoras de poucas ligações. Quanto maior o número de laços existentes, maior é a coesão do grupo (SCOTT, 2000; HATALA, 2006).

No caso em discussão, o elemento densidade da rede apresentou um índice final de 0,554, considerando uma escala que varia entre o e 1, com três casas decimais. Logo, é possível afirmar que a densidade é mediana entre os participantes do APL de Móveis do Sudoeste do Paraná.

Seguindo com a análise da densidade da rede, é importante também observar as relações sociais estabelecidas a partir da visualização do sociograma gerado nessa rede social, o qual pode ser visto na figura 3. Em suma, o sociograma utiliza mecanismos da teoria dos grafos para a conversão dos dados da matriz, com a formação de uma notação gráfica em que cada ponto ou nó representa um ator, e as linhas representam os laços e as conexões existentes (WASSERMAN; FAUST, 1994; SCOTT, 2000).

Diante do exposto, foi possível perceber que os agentes com maior proximidade ao centro dessa rede são respectivamente: SINDIMADMOV, SESISENAI-PR, os empresários associados, a FIEP e o SEBRAE-PR. Em contrapartida, a figura 3 também revela que a governança local do APL está posicionada bem distante do centro da rede, situada em uma região periférica, bem como ocorreu com a Associação Comercial e Empresarial de Francisco Beltrão - ACEFB.

Figura 3. Sociograma para a representação da densidade do Arranjo Produtivo Local

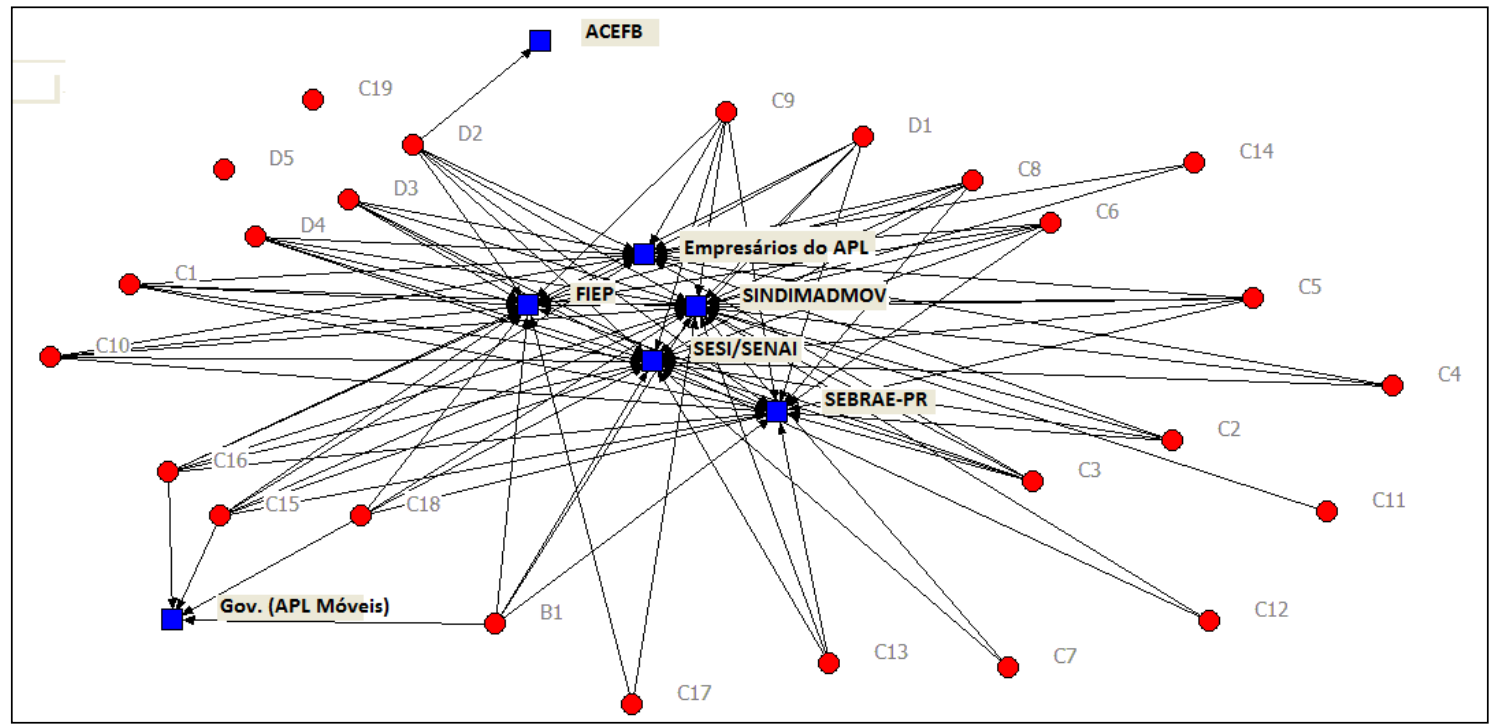

Fonte: elaborado pelos autores.

Na aplicação da metodologia de Análise de Redes Sociais - ARS também é interessante analisar o nível de reciprocidade entre os participantes do APL. A reciprocidade diz respeito ao relacionamento de concordância e mutualidade entre os agentes da rede, mensurando o nível de simetria entre os atores que a formam, possibilitando assim, identificar a sua coesão social. As relações são consideradas 
simétricas quando "i” escolhe "j" e "j" também escolhe "i" (WASSERMAN; FAUST, 1994; (HATALA, 2006).

A análise da reciprocidade no APL foi avaliada a partir de uma questão em que os entrevistados assinalaram quais dos agentes consideravam mais próximos, ou seja, aqueles com maior afinidade para trocar informações e estabelecer relações construtivas, além das reuniões formais da entidade.

Nesse quesito, o nível de reciprocidade do APL atingiu o valor de 0,750, podendo ser considerado bom, pois o indicador varia em uma escala entre 0 e 1 , com três casas decimais. Ademais, essa análise também possibilitou identificar os agentes do APL que possuem maior número de laços simétricos, a partir da visualização dos laços em cor azul no sociograma apresentado na figura 4. Logo, a pesquisa explicitou os agentes que apresentam apenas laços simétricos neste arranjo, correspondendo ao SEBRAE-PR e à FIEP.

Em síntese, os resultados demonstram que existe um bom grau de relacionamento entre os participantes desta rede. Porém, a pesquisa também revelou que o agente que não possui nenhum laço simétrico é a governança local do APL, o que pode ser justificado pela ausência atual de uma presidência neste arranjo produtivo, como já foi apresentado no quadro 1.

Figura 4. Sociograma para a representação da reciprocidade do Arranjo Produtivo Local

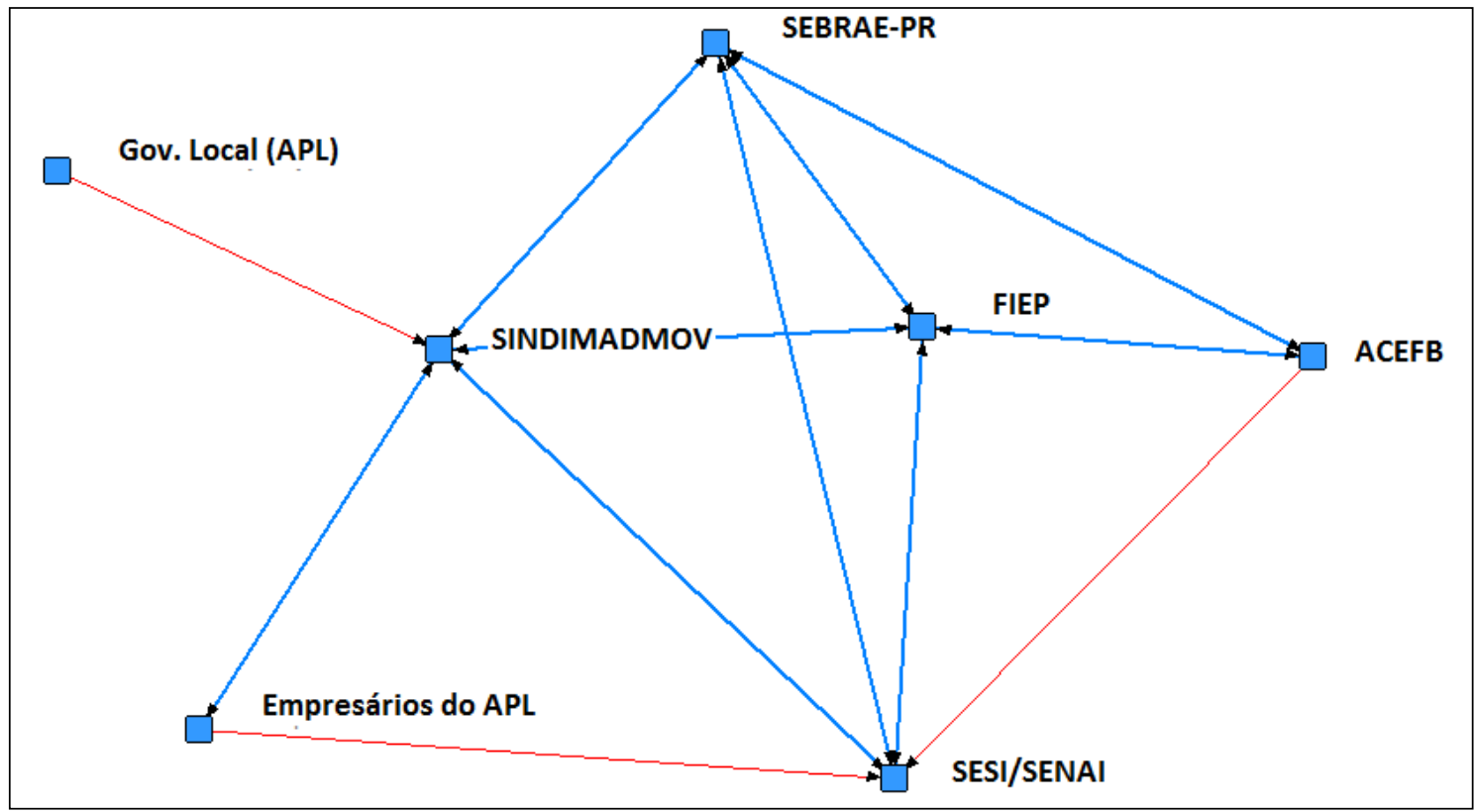

Fonte: elaborado pelos autores.

A partir da compilação dos resultados dos elementos propostos para a análise do capital social dos participantes do APL de Móveis do Sudoeste do Paraná, optou-se em elaborar um quadro síntese com base na escala proposta anteriormente, atribuindo também uma cor diferente para cada item da escala, conforme pode ser visto na legenda apresentada no quadro 2.

Nesse sentido, é possível observar que a maioria dos quesitos avaliados quanto ao capital social deste arranjo produtivo situaram-se na faixa "BOM" da 
escala (em cor verde), e apenas a "contribuição do relacionamento do APL", atribuída pelos empresários, ficou classificada como "ÓTIMO". Contudo, ressalta-se que os quesitos referentes à "participação nas reuniões do APL" apresentaram os piores resultados, classificados na escala como "FRACO".

Após a discussão dos resultados com a análise do capital social, encaminhase para a avaliação dos elementos relacionados à condução da governança local do APL de Móveis do Sudoeste do Paraná. A visualização inicial dos resultados apresentados no quadro 2 demonstram que todos os indicadores analisados para a governança local ficaram situados na faixa considerada como "FRACO" na escala proposta.

\section{Quadro 2. Síntese da análise do binômio}

\begin{tabular}{|c|c|c|c|}
\hline $\begin{array}{l}\text { Elementos do } \\
\text { CAPITAL SOCIAL }\end{array}$ & $\begin{array}{l}\text { Média } \\
\text { Geral }\end{array}$ & $\begin{array}{c}\text { Elementos da } \\
\text { GOVERNANÇA LOCAL }\end{array}$ & $\begin{array}{l}\text { Média } \\
\text { Geral }\end{array}$ \\
\hline Confiança dos Agentes & 6,40 & Capacidade de Coordenação & 4,1 \\
\hline Confiança nos Agentes de Apoio & 6,80 & Capacidade de Articulação & 4,1 \\
\hline Cooperação entre os Agentes & 5,90 & Poder na Resolução de Conflitos & 4,2 \\
\hline Participação em Reuniões - Empresários (\%) & $31 \%$ & Transparência na Gestão & 4,3 \\
\hline Participação em Reuniões - Agentes de Apoio (\%) & $40 \%$ & Práticas Democráticas & 2,6 \\
\hline Contribuição do Relacionamento - Empresários & 8,20 & Dificuldades da Governança Local & 4,2 \\
\hline Efetiva Participação em Reuniões - Empresários & 4,10 & \multirow{9}{*}{$\begin{array}{r}\text { Legenda } \\
\text { ÓTIMO }=7,51 \text { a } 10,00 \\
\text { BOM }=5,01 \text { a } 7,50 \\
\text { FRACO }=2,51 \text { a } 5,00 \\
\text { BAIXO }=0,00 \text { a } 2,50\end{array}$} & \\
\hline Contribuição do Relacionam. - Agentes de Apoio & 6,20 & & \\
\hline Efetiva Participação Reuniões - Agentes de Apoio & 5,00 & & \\
\hline Qualidade e Utilidade das Informações Trocadas & 7,30 & & \\
\hline Troca de Informações dos Agentes > mensal & $32 \%$ & & \\
\hline Grau de Engajamento e Envolvimento & 4,80 & & \\
\hline Contribuição no Conjunto do APL & 7,00 & & \\
\hline Densidade & 0,55 & & \\
\hline Reciprocidade & 0,75 & & \\
\hline
\end{tabular}

Fonte: elaborado pelos autores.

Inicialmente, é necessário retomar brevemente o contexto da linha históricotemporal quanto à definição para o cargo principal na governança local deste arranjo produtivo, a partir das informações apresentadas anteriormente no quadro 1. Este APL formalizou suas atividades como uma rede de cooperação territorial no ano de 2006, adotando uma política bianual para a função de presidente do arranjo produtivo, ou seja, a cada dois anos ocorreram eleições para definir quem assume a governança no próximo biênio.

Contudo, nos primeiros dois biênios (2006-2009), a governança local foi assumida por um mesmo empresário e, nos três biênios seguintes (2010-2015), outra empresária assumiu a presidência do APL. Dessa forma, fica evidente que mesmo em dez anos, ou seja, cinco mandatos, apenas duas pessoas assumiram a governança local. De certo modo, essa informação pode ser vista como um fator 
positivo, pois diminui a rotatividade no cargo e amplia as condições para a implementação e gestão de um plano de desenvolvimento para o APL.

Porém, de outro ângulo, é possível perceber, inclusive pela atual vacância nessa função (2016-2017), que nenhum empresário se dispôs a assumi-la voluntariamente, no período recente, o que implica em vacância na condução do arranjo produtivo. Nesse sentido, cabe destacar que a própria caracterização de um APL depende de um sistema de governança que permita e sincronize o relacionamento entre os agentes participantes da rede, como entidades públicas, universidades, agentes de apoio, bancos, associações, entre outros (VILPOUX, 2010).

Diante do exposto, é possível afirmar que essa condição apresentou uma implicação direta na avaliação da governança local, como pode ser visto nos resultados apresentados no quadro 2. Outrossim, ainda é importante destacar que para esta avaliação, os entrevistados foram orientados a responder as questões a partir de um olhar no indicador considerando cada quesito nos últimos cinco anos, ou seja, em um período temporal onde o APL possuía uma governança local institucionalizada.

A partir da compilação dos resultados que foram apresentados no quadro 2, é possível perceber que o quesito que buscou identificar o funcionamento do APL quanto às "práticas democráticas" obteve o pior desempenho na avaliação da governança local do APL.

Adicionalmente, considerando que foi utilizada uma escala de 0 até 10, todos os demais quesitos analisados (coordenação do APL = 4,1; capacidade de articulação para o desenvolvimento de ações conjuntas $=4,1$; resolução de conflitos $=4,2$; transparência na gestão = 4,3; dificuldades na condução da governança local = 4,2) resultaram em indicadores com desempenho considerado "FRACO" na escala proposta para essas discussões.

Diante do exposto, depreende-se que este APL encontra-se em fase embrionária, pois necessita formalizar um sistema de governança local, inclusive com a participação de agentes de apoio no processo, como sugerem alguns empresários entrevistados e estudiosos do tema, como exemplo: Cassiolato e Szapiro (2003); Suzigan, Garcia e Furtado (2007); Campos e Caleffi (2009), entre outros.

Nesse sentido, ressalta-se que os elementos do capital social que estão mais fragilizados nos resultados apresentados no quadro 2 correspondem àqueles relacionados ao nível de engajamento, comprometimento e participação em reuniões, os quais derivam de uma relação direta com a fraca avaliação atribuída pelo conjunto de entrevistados à governança local do APL, pois possuem implicação direta neste binômio.

Ademais, deve-se considerar a importância da governança local para o fortalecimento e agregação do capital social do arranjo produtivo, como foi apresentado na Figura 1, onde a matriz proposta por Marini et al. (2012) destaca a forte interdependência entre o binômio capital social e governança local para a realização de ações conjuntas no APL. No caso estudado, evidencia-se que a falta de confiança na governança local tem prejudicado a participação em ações conjuntas, além de causar a falta de comprometimento dos participantes nesta rede, e ainda 
enfraquecer os elementos do capital social, o que também implica em desestimular o próprio interesse para a condução da governança local do arranjo produtivo.

A atual ausência de governança local implica na falta de instrumentos de monitoramento, bem como na falta de planejamento e objetivos claros. Nesse contexto, se houver uma tentativa de dominação da coordenação por parte de empresas âncoras, a participação de empresas menores pode ser prejudicada devido à falta de confiança que se instala a partir de um relacionamento instável, ocasionando a falta de interesse, oportunismo de alguns agentes, baixa participação em reuniões, entre outros problemas (CASAROTTO FILHO; PIRES, 2001; TAPIA, 2005; SUZIGAN; GARCIA; FURTADO, 2007; CAMPOS; CALEFFI, 2009; MARINI et al., 2012).

\section{Considerações finais}

A literatura aponta a importância da organização dos atores locais e regionais para a cooperação territorial em busca da construção de vantagens competitivas, em que os APLs podem ser considerados uma das estratégias para o desenvolvimento territorial. Nesse sentido, o presente artigo buscou analisar os elementos do capital social e da governança local do APL de Móveis do Sudoeste do Paraná.

Com base em uma breve contextualização do cenário de investigação, foi possível relatar que, a partir dos anos 1930, todas as atividades da indústria regional do Sudoeste do Paraná se desenvolveram a partir da atividade extrativista madeireira ou estiveram muito ligados a ela, como é o caso da fabricação de móveis, que foi expandindo ao longo dos anos, culminando com a formalização do arranjo produtivo no ano de 2006.

Para o cumprimento do principal propósito de discussão deste artigo, foi realizada uma pesquisa de campo, com a aplicação de um questionário estruturado com o conjunto de participantes deste arranjo produtivo, incluindo 19 empresários do APL, cinco agentes de apoio e a governança local.

Inicialmente, buscou-se analisar um conjunto de elementos relacionados ao capital social dos participantes deste APL, a partir de um conjunto de elementos que foram avaliados pelos entrevistados em uma escala numérica variando entre 0 e 10, com a posterior estratificação em uma classificação baseada em quatro níveis (BAIXO, FRACO, BOM, ÓTIMO).

Em síntese, o índice médio de confiança entre os agentes ficou em 6,8 (BOM), porém, a governança local do APL apresentou o pior resultado neste quesito, com a confiança resultando em 2,6 (FRACO). Ainda assim, o nível de relacionamento resultando em 8,2 (ÓTIMO), o grau de contribuição no APL atribuído em 6,2 (BOM), além do índice de troca de informações de 7,3 (BOM), demonstraram que existem condições favoráveis para o desenvolvimento deste arranjo produtivo. Contudo, os atuais níveis de cooperacão entre os agentes que resultaram em 5,9, o engajamento e comprometimento avaliado em 4,8 e os baixos índices de participação em reuniões que resultaram em 4,1, sinalizam para a necessidade de urgente estruturação de uma governança para o APL.

Em consonância com essas discussões, prosseguiu-se com a análise das ações adotadas pela governança local no processo de condução do APL, as quais 
foram identificadas por meio de um conjunto de seis elementos baseados na literatura, com os entrevistados considerando um recorte temporal dos últimos cinco anos.

Como resultado inicial, cabe destacar que a pesquisa de campo revelou que, atualmente, não está formalizada uma governança local para o APL, pois, desde o mandato anterior (final do ano de 2015) até o momento, nenhum dos participantes assumiu a gestão do arranjo produtivo. Contudo, o atual presidente do SINDIMADMOV, que assumiu o sindicato em dezembro de 2017, informou na entrevista que está sendo discutida internamente a possibilidade de formalização de uma nova governança para o APL, visando restabelecer a condução e o planejamento deste APL.

Considerando esse período de vacância da governança local entre os anos de 2016 e 2017, é possível perceber que todos os indicadores levantados quanto à avaliação do processo de coordenação do arranjo resultaram em valores baixos, sinalizando para essa ausência atual de gestão deste APL.

Em síntese, a média para o grau da capacidade de coordenação (gestão do APL) ficou em 4,1; a capacidade de articulação (concertação social, diálogo e ajuda mútua) foi avaliada com média de 4,1; o poder de influência na resolução de conflitos resultou em um índice médio de 4,2; a média para o quesito que avaliou a transparência na gestão ficou em 4,3; as dificuldades para a condução da governança local também ficou em 4,2; e, as práticas democráticas na tomada de decisão resultaram no pior resultado, sendo atribuído o valor médio de 2,6.

Adicionalmente a esse debate, merecem especial atenção alguns apontamentos que os entrevistados indicaram como preocupantes para a efetiva construção de práticas cooperativas territoriais entre os participantes deste APL, incluindo: falta de união dos empresários; indisponibilidade de tempo para atuar na governança local ; falta de comprometimento e interesse dos agentes desta rede para participar de reuniões; falta de recursos financeiros para projetos conjuntos; pouca participação dos agentes de apoio na coordenação do APL; entre outros.

Diante do exposto, é possível afirmar que uma das principais limitações para o desenvolvimento desta pesquisa consistiu na atual vacância existente na função de coordenação da governança local do APL. Contudo, ressalta-se que os indicadores da pesquisa em relação à avaliação da governança local, mesmo que possam ficar prejudicados por essa limitação, corresponderam a um retrato fidedigno do atual cenário encontrado no caso estudado.

Outra possível limitação da pesquisa está no fato de que os empresários associados ao sindicato patronal geralmente confundem a atuação do APL com as ações promovidas pelo SINDIMADMOV, o que pode gerar distorções na interpretação das questões relacionadas especificamente ao arranjo produtivo. Porém, ressalta-se que a entrevista presencial entre o pesquisador e cada empresário contribuiu para que essa questão fosse minimizada.

Por fim, é importante destacar que existe a pretensão dos participantes pela retomada do APL, a partir de uma reestruturação de sua governança local, incluindo a possibilidade de inclusão de outros agentes de apoio nesta coordenação. Nesse sentido, ressalta-se que essa consciência coletiva sobre a importância da governança local para o funcionamento do arranjo produtivo é fundamental para a 
implementação de ações conjuntas pelos participantes do arranjo, o que ficou evidente na matriz de interdependência para APLs que foi apresentada na figura 1.

Em síntese, a avaliação do binômio capital social e governança local demonstrou que, para a efetiva execução de ações conjuntas em consonância com as práticas de cooperação territorial, torna-se fundamental a existência de uma governança local mais atuante na gestão do APL.

Como encaminhamento para trabalhos futuros, sugere-se a reedição desta pesquisa, visando uma nova análise neste APL, o que possibilitará comparar o binômio capital social e governança local nesses dois momentos distintos, bem como as suas possíveis implicações para as práticas de cooperação territorial.

\section{REFERÊNCIAS}

ABRAMOVAY, R. O capital social dos territórios: repensando o desenvolvimento rural - Revista de Economia Aplicada-volume 4, n², abril/junho 2000.

AGÊNCIA, Agência de Desenvolvimento Regional do Sudoeste do Paraná (Coord.). Estudo das Cadeias Produtivas Propulsivas do Sudoeste do Paraná. Plano de Desenvolvimento Regional Integrado (PDRI). Disponível em: <http://pdri.agenciasudoeste.org.br/p/11> acessado em 20/10/2016.

ALBAGLI., S.; MACIEL, M. L. Capital social e empreendedorismo local: proposição de políticas para a promoção de sistemas produtivos locais de micro, pequenas e médias empresas. Rio de Janeiro: Ed. UFRJ, 2002.

CAMPOS, A. C. Arranjos Produtivos no Estado do Paraná: o caso do município de Cianorte. (Tese de Doutorado), Curitiba, UFPR, 2004.

CAMPOS, A. C.; CALLEFI, P. Arranjos Produtivos Locais de confecção no Paraná: uma análise comparativa. Informe Gepec (Impresso), Toledo, v. 13, n. 2, p. 85-103, jul./dez. 2009.

CASAROTTO FILHO, N.; PIRES, L. H. Redes de pequenas e médias empresas e desenvolvimento local: estratégias para a conquista da competitividade global com base na experiência italiana. $2^{\text {a }}$ ed. São Paulo: Atlas, 2001.

CASSIOLATO, J. E.; LASTRES, H. M. M. O foco em arranjos produtivos e inovativos locais de micro e pequenas empresas. In: LASTRES, H. M. Martins; CASSIOLATO, J. E.; MACIEL, M. L. (Orgs.). - Pequena Empresa: Cooperação e Desenvolvimento Local. Rio de Janeiro: Dumará, 2003.

CASSIOLATO, J. E.; SZAPIRO, M. Uma caracterização de arranjos produtivos locais de micro e pequenas empresas. In: LASTRES, H. M. M; CASSIOLATO, J. E; MACIEL, M. L. (Org.). Pequena empresa: cooperação e desenvolvimento local. Rio de Janeiro: Relume Dumará, 2003. 
CASTRO, M. de. Contexto Institucional de Referência, Governança de Redes e Processos de Cooperação e Coopetição: estudo em Arranjos Produtivos Locais do Estado Paraná. Tese apresentada ao Programa de Pós-Graduação em Administração da Universidade Federal do Paraná/PPGADM UFPR. Curitiba PR. 2013.

COLEMAN, J, S. Social Capital in the Creation of Human Capital. The American Journal of Sociology, Vol. 94. Supplement: Organizations and Institutions:

Sociological and Economic Approaches to the Analysis of Social Structure. p. S95S120, 1988.

COSTA, E. J. M. da. Arranjos Produtivos Locais, Políticas Públicas e Desenvolvimento Regional. Ministério da Integração Nacional - Governo do Estado do Pará - IDESP. Brasília: Mais Gráfica Editora, 2010.

DALLABRIDA, V. R.; BECKER, D. F. Governança Territorial: Um primeiro passo na construção de uma proposta teórico-metodológica. Desenvolvimento em Questão, ljuí/RS, ano 1, n. 2, p. 73-98, jul./dez.,2003.

FARAH JR, M. F. et al. Arranjos Produtivos Locais e a Experiência do Paraná. In: XIII SIMPEP. Bauru (SP), nov./2006.

FLORES, E. L. Industrialização e Desenvolvimento do Sudoeste do Paraná Dissertação de mestrado - UNIOESTE- Francisco Beltrão. 2009

FUINI, L. L. A Governança em Arranjos Produtivos Locais (APLs): Algumas Considerações Teóricas e Metodológicas; Geografia (Londrina) v. 23, n.1, p. 57 83, jan/jun, 2014.

GAZIRI, L. C. Condicionantes da Inovação na Indústria Moveleira do Paraná. Dissertação de Mestrado - PPGMOD - FAE Centro Universitário - Curitiba. 2010.

GIL, A. C. Como elaborar projetos de pesquisa. $4^{\text {a }}$ edição: São Paulo: Atlas, 2008.

GRANOVETTER, M. Economic action and social structure: the problem of embeddedness. American Journal of Sociology. v. 91, n. 3, p. 481-510, 2007.

HATALA, J. P. Social Analysis in Human Resource Development: A New Methodology. Human Resource Development Review. Vol 5, 1, P 49-71, mar 2006.

MARINI, M. J.; SILVA, C. L. da; NASCIMENTO, D. E. do; STRAUHS, F.do R. Avaliação da contribuição de arranjos produtivos locais para o desenvolvimento local. Biblio 3W. Revista Bibliográfica de Geografía y Ciencias Sociales.Vol. XVII, nº 996 [En línea]. Barcelona: Universidad de Barcelona, 15 de octubre de 2012. 
MARINI, M. J.; SILVA, C. L. da. Aglomerações industriais: um estudo de caso da governança local do APL de Confecções do Sudoeste do Paraná. In: XV Congresso de Gestão de Tecnologia Latino-lberoamericano - ALTEC. Porto, Portugal, 2013.

MEIRELLES JUNIOR, J. C. Políticas públicas para os arranjos produtivos locais (APLs): uma visão estratégica. Revista "Vianna Sapiens", v. 3, p. 140-167, 2013.

NORTH, D. C. Structure and Change in Economic History. Norton. New York, 1981. Institutions, Institutional Change and Economic performance, Cambridge University Press, 1990.

ORTEGA, A. C.; SILVA, F. P. M. da. Uma visão crítica do Desenvolvimento Territorial e dos Novos Espaços de Governança. RDE- Revista de Desenvolvimento Econômico, n. 23, Salvador, 2011.

PARANÁ, Caracterização estrutural do APL de Móveis do Sudoeste do Paraná: estudo de caso / Universidade Estadual do Oeste do Paraná, Instituto Paranaense de Desenvolvimento Econômico e Social - IPARDES; Secretaria de Estado do Planejamento e Coordenação Geral. Curitiba. IPARDES, 2006.

. Identificação e mapeamento das aglomerações produtivas do Paraná: atualização 2008 / Instituto Paranaense de Desenvolvimento Econômico e Social. Curitiba: IPARDES, 2009.

. Perfil da Região Geográfica do Sudoeste Paranaense. Instituto Paranaense de Desenvolvimento Econômico e Social. IPARDES. Disponível em:<http://www.ipardes.gov.br/perfil_municipal/MontaPerfil.php?codlocal=707\&bt Ok=ok $>$ Acessado em 05 de agosto de 2016.

PUTNAM, R. D. Comunidade e democracia: a experiência da Itália moderna. Rio de Janeiro: Editora Fundação Getúlio Vargas, 1996.

SABOURIN, E.; TEIXEIRA, O A. Planejamento e Desenvolvimento dos Territórios Rurais: conceitos, controvérsias e experiências. Brasília: Embrapa/Cirad/UFPB, 2002.

SCOTT, J. Social Network Analysis: a handbook. 2 ed., London: Sage Publications, 2000.

SUZIGAN, W. (Coord.). Identificação, mapeamento e caracterização estrutural de arranjos produtivos locais no Brasil. Relatório Consolidado, IPEA-DISET, out.2006.

SUZIGAN, W.; GARCIA, R.; FURTADO, J. Estruturas de governança em arranjos ou sistemas locais de produção. Gestão \& Produção, São Carlos, v. 14, n. 2, p. 425439, maio-ago. 2007. 
TAPIA, J. R. B. Desenvolvimento Local, Concertação e Governança: a experiência dos pactos territoriais na Itália; São Paulo em Perspectiva, v. 19, n. 1, p. 132-139, jan./mar. 2005.

TEIXEIRA, A. F.; SERRALVO, F. A. Capital social em um Arranjo Produtivo Local: estudo da indústria têxtil e de confecção do Município de Americana e Região. Dissertação (Mestrado em Administração) - Pontifícia Universidade Católica de São Paulo, 2010.

VILPOUX, F. O.; OLIVEIRA, E. J. Instituições Informais e Governança em Arranjos Produtivos Locais. Revista Economia Contemporânea. Rio de Janeiro. V. 14, n. 1, p.85-111, jan./abr.2010.

WASSERMAN, S.; FAUST, K. Social Network Analysis: Methods and Applications. New York: Cambridge Press, 1994.

WOOLCOCK, M. et al. Measuring Social Capital: An Integrated Questionnaire. The World Bank Working Paper. Washington, The World Bank, n. 18, 2003.

Marcos Junior Marini. Professor do quadro permanente do Programa de PósGraduação (mestrado) em Desenvolvimento Regional (PPGDR). Coordenador do Laboratório de Estudos Regionais. Líder da Linha de Pesquisa Regionalidade e Desenvolvimento.marini@utfpr.edu.br

Gilcindo de Castro Corrêa Neto. Universidade Tecnológica Federal do Paraná (UTFPR). Mestrando do Programa de Pós-Graduação em Desenvolvimento Regional (PPGDR).gcorrea@pr.sebrae.com.br

Como citar: MARINI, Marcos Junior; CORRÊA NETO, Gilcindo de Castro. Cooperação territorial: análise do capital social e da governança local do APL de Móveis do Sudoeste do Paraná. Redes, Santa Cruz do Sul, v. 23, n. 3, p. 117-139, sep. 2018. ISSN 1982-6745. doi: https://doi.org/10.17058/redes.v23i3.12225. 